DAVIES, Lorenice Freire; KASSLER, Márcia Samuel. A apropriação ambiental no sistema de patentes biotecnológicas e a perspectiva de inclusão dos conhecimentos tradicionais como direito. Revista Eletrônica Direito e Política, Programa de Pós-Graduação Stricto Sensu em Ciência Jurídica da UNIVALI, Itajaí, v.10, n.1, edição especial de 2015. Disponível em: www.univali.br/direitoepolitica - ISSN 1980-7791.

\title{
A APROPRIAÇÃO AMBIENTAL NO SISTEMA DE PATENTES BIOTECNOLÓGICAS E A PERSPECTIVA DE INCLUSÃO DOS CONHECIMENTOS TRADICIONAIS COMO DIREITO
}

THE APPROPRIATION OF THE ENVIRONMENT IN THE BIOTECHNOLOGICAL PATENT SYSTEM AND THE PERSPECTIVE OF INCLUSION OF TRADITIONAL KNOWLEDGE AS A RIGHT

Lorenice Freire Davies ${ }^{1}$

Márcia Samuel Kessler ${ }^{2}$

SUMÁRIO: Introdução; 1. A transformação do meio ambiente e dos conhecimentos tradicionais em propriedade particular; 2. A aplicação dos conhecimentos tradicionais na biotecnologia; 3. Implicações da mercantilização da natureza: a biopirataria; 4. Perspectivas rumo à proteção da sociobiodiversidade; Considerações finais; Referências das fontes citadas.

RESUMO: A presente pesquisa consiste no questionamento do atual tratamento jurídico e político dos direitos intelectuais coletivos. Tem-se por objetivo abordar como o sistema de propriedades, dentre ela a intelectual, serve como instrumento para que o ramo biotecnológico possa promover a apropriação da natureza e dos conhecimentos das comunidades tradicionais, contribuindo para a insustentabilidade ambiental. Como aportes metodológicos, utiliza-se a abordagem sistêmico-complexa, enfocando 0 caráter multidisciplinar da pesquisa. Como técnica de pesquisa emprega-se a análise bibliográfica, documental e de legislação aplicada. Como considerações finais, aponta-se que o atual sistema de propriedade intelectual acarreta inúmeros reflexos, com destaque para a não repartição justa e equânime dos benefícios oriundos da biotecnologia, sendo necessário estabelecer um novo aporte jurídico, a fim de

\footnotetext{
1 Mestranda do Programa de Pós Graduação em Direito da Universidade Federal de Santa Maria (PPGD/UFSM), Santa Maria/RS, Brasil. Bolsista CAPES. Endereço eletrônico: loryfreire1@hotmail.com

2 Mestranda do Programa de Pós Graduação em Direito da Universidade Federal de Santa Maria (PPGD/UFSM), Santa Maria/RS, Brasil. Bolsista CAPES. Endereço eletrônico: marcia.kessler@gmail.com
} 
DAVIES, Lorenice Freire; KASSLER, Márcia Samuel. A apropriação ambiental no sistema de patentes biotecnológicas e a perspectiva de inclusão dos conhecimentos tradicionais como direito. Revista Eletrônica Direito e Política, Programa de Pós-Graduação Stricto Sensu em Ciência Jurídica da UNIVALI, Itajaí, v.10, n.1, edição especial de 2015. Disponível em: www.univali.br/direitoepolitica - ISSN 1980-7791.

proteger efetivamente os direitos intelectuais coletivos das comunidades tradicionais.

Palavras-chave: conhecimentos tradicionais; propriedade intelectual; biotecnologia; meio ambiente; sustentabilidade.

ABSTRACT: This paper aims in questioning the current legal and political treatment of the collective intellectual rights. The main objective is to addressing how the properties system, among them the intellectual one, serves as an instrument for the biotechnological industry to promote the appropriation of nature and the appropriation of the traditional knowledge, contributing to the environmental unsustainability. As methodological instrument is used the systemic-complex approach, focusing on the multidisciplinary nature of the research. As a research technique is used the bibliographic, documentary analysis and applied legislation. As conclusion, it is pointed out that the current intellectual property system entails numerous reflexes, especially not fair and equitable sharing of benefits arising from biotechnology, being necessary to establish a new legal input in order to effectively protect the collective intellectual rights of traditional communities.

Keywords: traditional knowledge; intellectual property; biotechnology; environment; sustainability.

\section{INTRODUÇÃO}

A natureza e os recursos ambientais sempre possuíram grande relevância para a história da humanidade, contudo a noção conceitual acerca da natureza foi adotada de forma diversa pelas sociedades no decorrer dos séculos. Com o capitalismo, cria-se um paradoxo na tentativa de compatibilização entre natureza e a economia. Nesse sentido, a natureza é considerada o valor primordial da economia, o primeiro bem passível de ser apropriado pelo homem, ou seja, é a primeira fonte de capital, motivo pelo qual os recursos naturais são inúmeras vezes utilizados com o objetivo de gerar riqueza.

Nesse cenário, na atualidade, em razão do capitalismo e da economia de mercado estarem voltados principalmente à obtenção de lucro, sem a preocupação com o meio ambiente, a natureza sofre desfalques, muitas vezes impossíveis de serem remediados, o que gera também a "colonização do outro". A avidez por lucros e acumulação de capital promovem um estreitamento na forma de enxergar o outro, permitindo a alguns indivíduos somente percorrer o 
DAVIES, Lorenice Freire; KASSLER, Márcia Samuel. A apropriação ambiental no sistema de patentes biotecnológicas e a perspectiva de inclusão dos conhecimentos tradicionais como direito. Revista Eletrônica Direito e Política, Programa de Pós-Graduação Stricto Sensu em Ciência Jurídica da UNIVALI, Itajaí, v.10, n.1, edição especial de 2015. Disponível em: www.univali.br/direitoepolitica - ISSN 1980-7791.

menor caminho para a obtenção de vantagens e mais recursos.

Tem-se uma corrida gananciosa pela transformação de biotecnologia ${ }^{3}$, com a fixação de patentes, segregando as mais diversas formas de conhecimentos tradicionais. Percebe-se, portanto, que existe uma verdadeira e desproporcional exploração realizada pelos países desenvolvidos em relação aos países subdesenvolvidos, que enseja diversos problemas, entre eles, a pilhagem da biodiversidade por meio da etnobioprospecção e dos direitos de propriedade intelectual, fato esse responsável por ocasionar diversos danos ao meio ambiente e ao próprio homem.

As comunidades tradicionais, tais como os quilombolas, as comunidades indígenas, as camponesas, as ribeirinhas, dentre outras, constituem a imensa diversidade cultural da humanidade. Seus conhecimentos tratam-se de uma modalidade de conhecimento coletivo, saberes e técnicas transmitidas de geração em geração, constituindo, assim, uma fonte cultural de riqueza imensurável, de titularidade pertencente a toda uma coletividade.

Nesse contexto, a problemática da pesquisa busca especificamente, responder as seguintes questões: Quais os reflexos do regime de propriedade intelectual? E quais as perspectivas (alternativas) de tutela dos direitos intelectuais coletivos? Para isso, se discorrerá sobre os atuais tratados que compõem o sistema patentário e se questionará a forma de mercantilização e apropriação da natureza, evidenciada no tratamento jurídico e político dos direitos intelectuais coletivos, especificamente, no sistema de propriedade intelectual.

Quanto à metodologia, utilizou-se como teoria de base e abordagem a matriz sistêmico-complexa, enfocando o caráter multidisciplinar da pesquisa decorrente do diálogo de saberes entre o Direito, Antropologia e Ecologia. Como técnica de pesquisa emprega-se a análise bibliográfica, por meio de documentos, doutrinas e de legislação aplicada.

O artigo é desenvolvido na estrutura de quatro seções. No momento inicial,

\footnotetext{
3 A biotecnologia, de acordo com a Convenção sobre a Diversidade Biológica (CDB) significa qualquer aplicação tecnológica que utilize sistemas biológicos, organismos vivos, ou seus derivados, para fabricar ou modificar produtos ou processos para utilização específica. BRASIL. Convenção sobre Diversidade Biológica [2000]. Disponível em: <http://www.mma.gov.br/biodiversidade/convencao-da-diversidade-biologica>. Acesso em: 20. dez.2013.
} 
DAVIES, Lorenice Freire; KASSLER, Márcia Samuel. A apropriação ambiental no sistema de patentes biotecnológicas e a perspectiva de inclusão dos conhecimentos tradicionais como direito. Revista Eletrônica Direito e Política, Programa de Pós-Graduação Stricto Sensu em Ciência Jurídica da UNIVALI, Itajaí, v.10, n.1, edição especial de 2015. Disponível em: www.univali.br/direitoepolitica - ISSN 1980-7791.

busca-se apresentar a transformação do meio ambiente e dos conhecimentos tradicionais em mercadoria, apresentando brevemente alguns dos principais tratados internacionais sobre o tema e a legislação nacional.

Na sequência, a segunda seção do artigo objetiva abordar a utilização dos conhecimentos tradicionais pela indústria biotecnológica e os impactos do seu uso. Na terceira seção, é tratada a questão da biopirataria em âmbito nacional, para que, por fim, se possam traçar na quarta seção as perspectivas mais pontuais na proteção dos direitos da sociobiodiversidade.

A relevância da pesquisa consiste na problemática sobre as formas de apropriação dos conhecimentos tradicionais associados à biodiversidade para fins comerciais, exclusivamente. Essas práticas mercadológicas subestimam os processos culturais das comunidades tradicionais, além de não promoverem a repartição dos benefícios com as comunidades.

A partir da presente análise, pondera-se a urgente e necessária discussão sobre o atual sistema de propriedade intelectual, visando novos caminhos e a propositura de alternativas ao embate dos direitos intelectuais coletivos e 0 monopólio da natureza.

\section{A TRANSFORMAÇÃO DO MEIO AMBIENTE E DOS CONHECIMENTOS TRADICIONAIS EM PROPRIEDADE PARTICULAR}

Ao se ter como ponto de partida a necessidade de reformulação da forma de proteção da propriedade intelectual dos povos tradicionais e da proteção ambiental, é preciso que se verifique que o processo de relacionamento estabelecido entre as sociedades e o meio ambiente passou por diversas etapas de desenvolvimento nos últimos séculos. Explica o jurista François Ost ${ }^{4}$ que a natureza era vista como uma propriedade simultânea, compartilhada entre diversos titulares. Individualmente, o que se tinha era uma forma de propriedade-usufruto da terra, como forma de proteção de um excesso em sua exploração, visto a necessidade do equilíbrio ecológico.

A partir dos séculos XVI a XIX, os fios de solidariedade que uniam os indivíduos

\footnotetext{
${ }^{4}$ OST, François. A natureza à margem da lei: a ecologia à prova do direito. Lisboa: Ed. Instituto Piaget, 1995.
} 
DAVIES, Lorenice Freire; KASSLER, Márcia Samuel. A apropriação ambiental no sistema de patentes biotecnológicas e a perspectiva de inclusão dos conhecimentos tradicionais como direito. Revista Eletrônica Direito e Política, Programa de Pós-Graduação Stricto Sensu em Ciência Jurídica da UNIVALI, Itajaí, v.10, n.1, edição especial de 2015. Disponível em: www.univali.br/direitoepolitica - ISSN 1980-7791.

por meio dos bens partilhados foram se desenlaçando e passou-se a conquistar o direito à propriedade privada. Com a apropriação privada ${ }^{5}$ houve a possibilidade de que os homens pudessem adquirir porções individuais distintas " (...) do que Deus deu aos homens em comum"6.

Com a aquisição do direito à propriedade individual, a forma de exercício de poderes sobre aquilo que se detém, se modifica. A propriedade que antes tinha um viés conservacionista, passa a preocupar-se com a circulação (compra, venda, locação) e, em um futuro breve, com a transformação ${ }^{7}$.

Em realidade, entende-se que o viés transformacionista ("propriedadetransformação") do meio ambiente já vigora, não sendo algo para o futuro próximo. São transformações que se implementam não somente no campo das ações, mas também no campo discursivo das formas de apropriação dos recursos naturais e dos conhecimentos tradicionais dos povos, na transformação de organismos vivos em matérias-primas.

Por meio desse processo de apropriação capitalista, desenvolveu-se o crescimento da importância da biotecnologia por meio do investimento em direitos da propriedade intelectual, no período de 1970 a 1990 . Os marcos para esse aumento de investimentos foram a aprovação do Plant Variety Protection Act, que instalou um sistema de patente para sementes nos Estados Unidos e também a decisão da Suprema Corte norte-americana que permitiu o patenteamento de um micróbio ${ }^{8}$.

Assim, a partir da valorização da biotecnologia, verifica-se na esfera internacional - aumento de conflitos de interesses entre a preservação/compensação/exploração dos recursos naturais por meio de negociações entre os países por meio de acordos. Um desses eventos ocorreu em 1992, no Rio de Janeiro, na Convenção da Diversidade Biológica (CDB).

Na CDB observa-se que aspectos ligados aos direitos de propriedade de

\footnotetext{
${ }^{5}$ Conforme afirma Carlos Walter Porto-Gonçalves a propriedade privada é pressuposto jurídico e político da economia mercantil capitalista moderna. O próprio termo em si, denota que a propriedade privada priva quem não é proprietário, tendo na escassez a base de sua economia. PORTO-GONÇALVES, Carlos Walter. O desafio ambiental. Rio de Janeiro: Record, 2004. p.57.

${ }^{6}$ LOCKE apud OST, François. A natureza à margem da lei: a ecologia à prova do direito.p.59.

7 OST, François. A natureza à margem da lei: a ecologia à prova do direito.p.54.

${ }^{8}$ HANNIGAN, John. Sociologia ambiental. p.178.
} 
DAVIES, Lorenice Freire; KASSLER, Márcia Samuel. A apropriação ambiental no sistema de patentes biotecnológicas e a perspectiva de inclusão dos conhecimentos tradicionais como direito. Revista Eletrônica Direito e Política, Programa de Pós-Graduação Stricto Sensu em Ciência Jurídica da UNIVALI, Itajaí, v.10, n.1, edição especial de 2015. Disponível em: www.univali.br/direitoepolitica - ISSN 1980-7791.

recursos genéticos e à propriedade intelectual geraram uma polarização entre países desenvolvidos e em desenvolvimento. De um lado, havia os países desenvolvidos ("ricos em biotecnologia"9), mediante lógica apropriacionista, entendendo o patrimônio genético como um "patrimônio comum", passível de exploração gratuita. De outro, os países em desenvolvimento ("ricos em recursos genéticos") entendiam que os recursos genéticos não eram "patrimônio comum", mas sim, recursos nacionais soberanos ${ }^{10}$.

No embate entre discursos, venceu o entendimento de que a proteção da biodiversidade é uma "preocupação comum". O texto final do acordo ao invés de determinar sanções ou obrigações, previu tão somente princípios a serem seguidos pelos países, deixando de prever instrumentos de regulação do acesso aos recursos genéticos e não contemplando adequadamente os direitos e interesses de comunidades tradicionais ${ }^{11}$.

Essa flexibilidade permitida ao acordo final da CDB, dando-lhe o caráter de soft law, permitiu que acordos posteriores impositivos pudessem prevalecer, bem como que legislações nacionais pudessem ser permissivas a posturas de vulnerabilização do meio ambiente. Foi o que ocorreu no dia seguinte ao encerramento à $\mathrm{CDB}$, quando o presidente à época enviou ao Congresso Nacional projeto de lei de patentes para permitir o acesso à biodiversidade sem qualquer compensação ${ }^{12}$. Em 6 de maio de 1993, aprovou-se a Lei de Propriedade Industrial que permitia o patenteamento de micro-organismos, regulamentando a proteção do acesso aos processos e produtos gerados pela indústria biotecnológica. Faltava ainda, no âmbito nacional, a regulamentação do acesso aos recursos genéticos ${ }^{13}$, o que foi posteriormente regulado por medidas provisórias (sendo a última delas a MP 2.186-16/2001), decretos e resoluções.

No âmbito internacional, continuando as discussões acerca dos direitos de

\footnotetext{
${ }^{9}$ INOUE, Cristina Yume Aoki. Regime global de biodiversidade: o caso Mamirauá. Brasília, Ed. Universidade de Brasília, 2007. p.69.

${ }^{10}$ INOUE, Cristina Yume Aoki. Regime global de biodiversidade: o caso Mamirauá. p.70.

${ }^{11}$ INOUE, Cristina Yume Aoki. Regime global de biodiversidade: o caso Mamirauá. p.70.

12 SANTOS, Laymert Garcia dos. Quando o conhecimento tecnocientífico se torna predação highttech: recursos genéticos e conhecimento tradicional no Brasil. In: SANTOS, Boaventura de Sousa (org.). Semear outras soluções: os caminhos da biodiversidade e dos conhecimentos rivais. Rio de Janeiro: Civilização Brasileira, 2005. p.127-165.

13 SANTOS, Laymert Garcia dos. Quando o conhecimento tecnocientífico se torna predação highttech: recursos genéticos e conhecimento tradicional no Brasil. p.142.
} 
DAVIES, Lorenice Freire; KASSLER, Márcia Samuel. A apropriação ambiental no sistema de patentes biotecnológicas e a perspectiva de inclusão dos conhecimentos tradicionais como direito. Revista Eletrônica Direito e Política, Programa de Pós-Graduação Stricto Sensu em Ciência Jurídica da UNIVALI, Itajaí, v.10, n.1, edição especial de 2015. Disponível em: www.univali.br/direitoepolitica - ISSN 1980-7791.

propriedade, a Organização Mundial do Comércio (OMC), realizou rodadas de negociação, que culminaram na imposição do Acordo sobre Aspectos dos Direitos de Propriedade Intelectual (TRIPs). A partir do estabelecimento do acordo TRIPs se delineou o atual sistema de patentes.

O TRIPs no entendimento de Carolyn Deere é a "(...) peça central do sistema global de regras, instituições e práticas de governança da propriedade e fluxo do conhecimento, tecnologia e outros ativos intelectuais" ${ }^{14}$. A assinatura do TRIPs representou uma revolução na história da proteção da propriedade intelectual por meio do estabelecimento de um conjunto universal e juridicamente vinculativo de normas de propriedade intelectual.

Conforme se observa, a redação final do acordo TRIPS foi resultado de um jogo intenso entre proponentes e aceitantes, marcado por altas apostas econômicas e sociais em um campo extremamente desigual, cujo resultado deixou ambas as partes insatisfeitas ${ }^{15}$. Exemplo disso, é o art. 27.3(b) do acordo TRIPS que consiste em ponto de divergência entre os países.

O artigo 27.3(b) apesar de prever a impossibilidade de patentamento de plantas e animais, abre uma exceção para microorganismos e processos essencialmente biológicos para produção de plantas e animais. Além disso, outro artigo que gera discordância é o art. 62 do acordo TRIPS, que exclui determinados aspectos dentre os requisitos para obtenção de patentes, dentre eles a identificação do país de origem dos recursos genéticos ou do conhecimento tradicional associado e prova de obtenção de consentimento prévio fundamentado e de repartição de benefícios.

Assim, observa-se que no campo político da proteção ambiental, há um desprivilégio com relação às preocupações dos povos tradicionais e com a elaboração de uma regulamentação mais clara e objetiva do uso de seus conhecimentos, o que gera incerteza e permite a utilização desses conhecimentos sem a devida compensação. Por essa razão, na seção seguinte se

\footnotetext{
${ }^{14}$ DEERE, Carolyn. The implementation game: the TRIPS Agreement and the Global Politics of intellectual property reform in developing countries. New York (EUA): Oxford University Press, 2011. p.1, tradução livre.

${ }^{15}$ DEERE, Carolyn. The implementation game: the TRIPS Agreement and the Global Politics of intellectual property reform in developing countries.
} 
DAVIES, Lorenice Freire; KASSLER, Márcia Samuel. A apropriação ambiental no sistema de patentes biotecnológicas e a perspectiva de inclusão dos conhecimentos tradicionais como direito. Revista Eletrônica Direito e Política, Programa de Pós-Graduação Stricto Sensu em Ciência Jurídica da UNIVALI, Itajaí, v.10, n.1, edição especial de 2015. Disponível em: www.univali.br/direitoepolitica - ISSN 1980-7791.

abordará a aplicação dos conhecimentos tradicionais na biotecnologia e suas implicações.

\section{A APLICAÇÃO DOS CONHECIMENTOS TRADICIONAIS NA BIOTECNOLOGIA}

O conhecimento tradicional dos povos indígenas, quilombolas e populações tradicionais é resultado de muitos anos de vivência e serve a esses povos como forma de relação com a natureza, fonte de seus medicamentos, alimentos e insumos para seus rituais e práticas culturais. Com a expansão do capital em busca de novas áreas de exploração, os conhecimentos desses povos tornaramse alvo de pesquisa e se constituíram em verdadeira "fonte" de investigação científica para obtenção de novos produtos, especialmente na área biotecnológica.

Assim, com a ampliação das investigações, percebeu-se que os saberes desses povos associados ao patrimônio genético das plantas e animais possui um valor muito maior que o bem ambiental por si só. Ao se tornar objeto de pesquisa da biotecnologia, esse conhecimento passa a ser uma forma de mercadoria que vai abastecer, dentre outros, o bilionário mercado de fármacos mundial, o qual se retroalimenta por meio da propriedade intelectual.

Conforme explica Antonio Carlos Diegues o que se observa é que o conhecimento científico ocidental se apropria do conhecimento tradicional dos povos e comunidades tradicionais transformando-os em mercadorias, retirando-os da coletividade onde foram construídos de forma solidária para inseri-los no mercado capitalista ${ }^{16}$. Tem-se, portanto, uma relação dual: de um lado, está o saber acumulado das populações tradicionais sobre os ciclos naturais, sobre a influência da lua nas atividades, sobre os sistemas de manejo dos recursos naturais; de outro, tem-se o conhecimento científico, que acaba por desconhecer e desprezar o conhecimento tradicional oralmente acumulado.

\footnotetext{
16 DIEGUES, Antonio Carlos. A educação ambiental e a questão das áreas naturais protegidas. dez. 2013. p.9.
} 
DAVIES, Lorenice Freire; KASSLER, Márcia Samuel. A apropriação ambiental no sistema de patentes biotecnológicas e a perspectiva de inclusão dos conhecimentos tradicionais como direito. Revista Eletrônica Direito e Política, Programa de Pós-Graduação Stricto Sensu em Ciência Jurídica da UNIVALI, Itajaí, v.10, n.1, edição especial de 2015. Disponível em: www.univali.br/direitoepolitica - ISSN 1980-7791.

A partir desse embate entre populações tradicionais e conhecimento científico, verifica-se também a existência de uma grande contradição entre o sistema de propriedade intelectual vigente e o modo de vida e conhecimentos dos povos indígenas e quilombolas relacionado à utilização do meio ambiente. Isso porque, enquanto o primeiro é concebido para ser excludente, monopolista, individual e privatista, o segundo é construído e utilizado tradicionalmente pelos seus detentores de forma coletiva, solidária e em harmonia com a natureza ${ }^{17}$.

Nesse contexto, o tratamento destrutivo dado à natureza em sua capitalização torna-se cada vez mais evidente com o recrudescimento das mudanças advindas do processo de transformação dos recursos naturais, por sua exploração descontrolada e insustentável. No entanto, os recursos naturais são limitados. A exigência de recursos produtivos e de riquezas em quantidades maiores e de fácil exploração, sejam renováveis ou não-renováveis, a partir das necessidades das economias desenvolvidas mostram que o planeta já chegou ao seu limite.

Não se pode admitir um modelo econômico excludente e iníquo. A substituição de capital natural pelo capital tecnológico e humano é possível, mas existem limites. O progresso humano ultrapassa os limites das leis da natureza, o âmbito econômico interfere nos elementos naturais, que regulam o seu equilíbrio como um todo. E, diante da temática da biodiversidade e propriedade intelectual, verifica-se um contexto de insustentabilidade na própria relação homemnatureza, de modo que a própria concepção e apropriação da natureza devem ser repensadas.

A autora Carol Proner observa que, "a propriedade intelectual, da forma como se regulamenta frente aos grandes capitais e legislada pelo Estado, determina um círculo vicioso de produção de miséria econômica e humana" e de destruição ${ }^{18}$. Essa dependência, assim, reforçada pela manutenção das trocas desiguais, decorrentes do aspecto mercadocêntrico de consideração do individualismopatrimonial, assevera a lógica do dominante e o dominado. E, nesta relação, o

17 DANTAS, Fernando Antonio de Carvalho. Los pueblos indígenas brasileños y los derechos de propiedad intelectual. In: RUBIO, David Sánches; ALFARO, Norman J. Solórzano; CID, Isabel V.Lucena (orgs). Nuevos colonialismos del capital. Propiedad intelectual, biodiversidad y derechos de los pueblos. Barcelona: Icaria Editoria, 2004. p.308.

18 PRONER, Carol. Propriedade Intelectual: para uma outra ordem jurídica possível. Cortez Editora, São Paulo: Brasil. $2007 . \quad$ Disponível <http://bibliotecavirtual.clacso.org.ar/ar/libros/varios/Proner_2007.pdf>. Acesso em: 20 dez.2013. p.74. 
DAVIES, Lorenice Freire; KASSLER, Márcia Samuel. A apropriação ambiental no sistema de patentes biotecnológicas e a perspectiva de inclusão dos conhecimentos tradicionais como direito. Revista Eletrônica Direito e Política, Programa de Pós-Graduação Stricto Sensu em Ciência Jurídica da UNIVALI, Itajaí, v.10, n.1, edição especial de 2015. Disponível em: www.univali.br/direitoepolitica - ISSN 1980-7791.

sistema de patentes, enquanto influenciado pela racionalidade econômica, não protege efetivamente a biodiversidade e direito dos povos, pois usado em nome daqueles que possuem avançada tecnologia e controle do mercado - Estados desenvolvidos e empresas transnacionais ${ }^{19}$.

A partir da constituição do sistema de patentes e da mercantilização dos conhecimentos tradicionais, percebe-se que são diversos os impactos causados ao ecossistema e às sociedades que dependem desses conhecimentos. Esse aspecto será abordado na seção posterior.

\section{IMPLICAÇÕES DA MERCANTILIZAÇÃO DA NATUREZA: A BIOPIRATARIA}

Conforme se identificou na seção anterior, os conhecimentos tradicionais associados à biodiversidade instigam o interesse da indústria biotecnológica. Por essa razão, a OMC e a Organização Mundial de Propriedade Intelectual (OMPI), legitimam as articulações entre os países, as quais permitem aos países desenvolvidos determinadas sobreposições de interesses diante dos menos desenvolvidos.

A partir da vinculação da biodiversidade e dos conhecimentos tradicionais à propriedade intelectual, verifica-se a existência de um reducionismo cientifico, tecnológico e mercantilizado do mundo ocidental. Essa postura de mercantilização por meio da propriedade intelectual, no âmbito da biotecnologia, gera impactos, dentre os quais destacam-se : a individualização do saber, a competitividade, o acúmulo de capital, a cobrança de royalties, o domínio sobre o conhecimento, a infiltração de empresas em territórios ricos em biodiversidade, a dependência dos países em desenvolvimento em relação às empresas multinacionais, que se apropriam dos recursos naturais e conhecimentos encontrados com os povos tradicionais gratuitamente ou por um valor ínfimo, dentre outras.

O conhecimento tradicional dos povos indígenas, quilombolas e populações tradicionais tornou-se alvo de pesquisa e se constituiu em verdadeira "fonte" de

19 RUBIO, David Sánchez; ALFARO, Norman J. Solórzano. Introdución. In: RUBIO, David Sánchez; ALFARO, Norman J. Solórzano; CID, Isabel V. Lucena (org.). Nuevos colonialismos del capital: propiedad intelectual, biodiversidad y derechos de los pueblos. Barcelona: Icaria, 2004. 
DAVIES, Lorenice Freire; KASSLER, Márcia Samuel. A apropriação ambiental no sistema de patentes biotecnológicas e a perspectiva de inclusão dos conhecimentos tradicionais como direito. Revista Eletrônica Direito e Política, Programa de Pós-Graduação Stricto Sensu em Ciência Jurídica da UNIVALI, Itajaí, v.10, n.1, edição especial de 2015. Disponível em: www.univali.br/direitoepolitica - ISSN 1980-7791.

investigação científica para obtenção de novos produtos, especialmente na área biotecnológica, estando estes saberes diretamente associados ao patrimônio genético das plantas e animais de onde as sociedades tradicionais retiram seus medicamentos, alimentos e insumos para seus rituais e práticas culturais. Os saberes desses povos tradicionais associado ao patrimônio genético tem um valor muito maior que o bem ambiental por si só, pois se torna objeto de pesquisa da biotecnologia ${ }^{20}$ e vai abastecer, dentre outros, o bilionário mercado de fármacos mundial, o qual se retroalimenta por meio da propriedade intelectual.

Pode-se, portanto, perceber que há grande contradição entre o sistema de propriedade intelectual vigente e o modo de vida e conhecimentos dos povos indígenas e quilombolas relacionado à utilização do meio ambiente. Enquanto o primeiro é concebido para ser excludente, monopolista, individual e privatista, o segundo é construído e utilizado tradicionalmente pelos seus detentores de forma coletiva, solidária e em harmonia com a natureza ${ }^{21}$.

Os conhecimentos científico e tradicional, associam-se para o avanço das pesquisas e, consequente, patenteamento. Ocorre que, muitos dos procedimentos científicos de pesquisa do potencial econômico, conforme a utilização dos conhecimentos tradicionais sobre os recursos naturais, após obter o êxito científico-econômico passam a desconsiderar e desrespeitar os conhecimentos das culturas locais.

$\mathrm{Na}$ tentativa de superar esta "ciência sem consciência", articula-se então sociedade e natureza para problematizar o conhecimento científico e tecnológico de uma racionalidade atrelada apenas às noções econômicas, alheia a realidade global e complexa ${ }^{22}$. Essa dependência, assim, reforçada pela manutenção das trocas desiguais, decorrentes do aspecto mercadocêntrico de consideração do individualismo-patrimonial, assevera a lógica do dominante e o dominado no contexto mercadológico e aos povos tradicionais, respectivamente.

\footnotetext{
20 A biotecnologia, de acordo com a CDB significa qualquer aplicação tecnológica que utilize sistemas biológicos, organismos vivos, ou seus derivados, para fabricar ou modificar produtos ou processos para utilização específica. BRASIL. Convenção sobre Diversidade Biológica [2000]. S.p.

21 DANTAS, Fernando Antonio de Carvalho. Los pueblos indígenas brasileños y los derechos de propriedad intelectual. p.308.

22 LEFF, Enrique. Saber Ambiental: sustentabilidade, racionalidade, complexidade. Trad. Lúcia Orth. Petrópolis, RJ: Vozes, 2011. p.138-139.
} 
DAVIES, Lorenice Freire; KASSLER, Márcia Samuel. A apropriação ambiental no sistema de patentes biotecnológicas e a perspectiva de inclusão dos conhecimentos tradicionais como direito. Revista Eletrônica Direito e Política, Programa de Pós-Graduação Stricto Sensu em Ciência Jurídica da UNIVALI, Itajaí, v.10, n.1, edição especial de 2015. Disponível em: www.univali.br/direitoepolitica - ISSN 1980-7791.

E, nesta relação, o sistema de patentes, enquanto influenciado pela racionalidade econômica, não protege efetivamente a biodiversidade e direito dos povos, pois usado em nome daqueles que possuem avançada tecnologia e controle do mercado - Estados desenvolvidos e empresas transnacionais ${ }^{23}$. Nesse sentido, para a autora Carol Proner, "torna-se necessário dotar o direito de valores que possam garantir a possibilidade de vida humana, sua continuidade em condições dignas. O saber deve ser instrumento da vida e não da morte de seres humanos"24.

Como visto, no regime de propriedade intelectual, os benefícios de uso do meio ambiente estão concentrados nas mãos de poucos, e os 'custos ambientais' são transferidos para os mais fracos, de modo a configurar a desigualdade social e de poder. Ou seja, "a desigualdade ambiental pode manifestar-se tanto sob a forma de proteção ambiental desigual como de acesso desigual dos recursos ambientais" 25

Assim, observa-se que grande parte dos impactos adversos da biotecnologia está relacionada com a evolução das novas tecnologias sob o controle do setor privado transnacional. As empresas transnacionais estão comprando a maioria das companhias que produzem sementes, controlando o mercado global, com interesse em produtos químicos, pesticidas e produtos farmacêuticos ${ }^{26}$.

A privatização é outro reflexo identificado, visto estar se tornando uma ameaça à democracia e à vontade dos povos. Isso ocorre porque os mesmos cientistas que trabalham sob contrato para as grandes empresas transnacionais atuam como consultores nos órgãos de regulamentação do governo e dominam a pesquisa científica ${ }^{27}$.

\footnotetext{
23 RUBIO, David Sánchez; ALFARO, Norman J. Solórzano. Introdución. p.61.

24 PRONER, Carol. Propriedade Intelectual: para uma outra ordem jurídica possível. p.74.

25 ACSELRAD, Henri; MELLO, Cecília Campello. O que é justiça ambiental. Rio de Janeiro: Garamond, 2009. p.73.

26 SHIVA, Vandana. Monoculturas da mente: (...). p.144.

27 SHIVA, Vandana. Monoculturas da mente: (...) p.145.
} 
DAVIES, Lorenice Freire; KASSLER, Márcia Samuel. A apropriação ambiental no sistema de patentes biotecnológicas e a perspectiva de inclusão dos conhecimentos tradicionais como direito. Revista Eletrônica Direito e Política, Programa de Pós-Graduação Stricto Sensu em Ciência Jurídica da UNIVALI, Itajaí, v.10, n.1, edição especial de 2015. Disponível em: www.univali.br/direitoepolitica - ISSN 1980-7791.

A produção baseada na uniformidade passou a ser a maior ameaça à sustentabilidade e à preservação da diversidade ${ }^{28}$. Assim, cabe aos cidadãos conseguirem espaço para o controle público das novas biotecnologias ${ }^{29}$.

Dentre as preocupações, em face da lógica mercadológica, consiste o risco posto às comunidades tradicionais no tocante à transformação de seus conhecimentos em mais uma mercadoria, podendo ser transacionada como qualquer artigo à disposição no mercado.

No que tange à definição de biopirataria, importa verificar que não existe uma definição propriamente jurídica do termo, sendo relativamente aceito como "atividade que envolve o acesso aos recursos genéticos de um determinado país ou aos conhecimentos tradicionais associados a tais recursos genéticos (ou a ambos) em desacordo com os princípios estabelecidos na Convenção sobre a Diversidade Biológica" ${ }^{30}$.

Quando a atividade envolver conhecimentos, inovações e práticas de povos indígenas e populações tradicionais, a CDB estabelece a necessidade de aprovação e participação de seus detentores, bem como a repartição dos benefícios com os mesmos. E como bem explica Vinícius Vieira Garcia:

A ilegitimidade das práticas é observada em processos de biopirataria, notadamente dos recursos de países latinoamericanos ilegalmente explorados por corporações com sede nos países do Norte, que buscam patentes para excluir as comunidades tradicionais dos benefícios gerados com a utilização dos recursos biológicos. Assim, a concessão de direitos de propriedade intelectual se opõe aos objetivos expressos na $\mathrm{CDB}^{31}$.

Assim, tem-se a conversão da biodiversidade em objetos de direitos de propriedade intelectual associados a mercadorias biotecnológicas que fomentam o comércio internacional.

\footnotetext{
${ }^{28}$ SHIVA, Vandana. Monoculturas da mente: perspectivas da biodiversidade e da biotecnologia. p.159.

${ }^{29}$ SHIVA, Vandana. Monoculturas da mente: (...). p. 145.

30 SANTILLI, Juliana. Socioambientalismo e novos direitos: proteção jurídica à diversidade biológica e cultural. São Paulo: Peirópolis, 2012. p.346.

31 VIEIRA, Vinícius Garcia. Direito da Biodiversidade e América Latina: a questão da propriedade intelectual. Ijuí; Unijuí, 2012. p.185.
} 
DAVIES, Lorenice Freire; KASSLER, Márcia Samuel. A apropriação ambiental no sistema de patentes biotecnológicas e a perspectiva de inclusão dos conhecimentos tradicionais como direito. Revista Eletrônica Direito e Política, Programa de Pós-Graduação Stricto Sensu em Ciência Jurídica da UNIVALI, Itajaí, v.10, n.1, edição especial de 2015. Disponível em: www.univali.br/direitoepolitica - ISSN 1980-7791.

A etnobiopirataria se dá pelo recolhimento de informações sistematizadas pelas comunidades de camponeses, indígenas ou afrodescendentes ${ }^{32}$. Já a atividade de bioprospecção possui correlação com envolve a atividade de coleta de material biológico e de acesso a seus recursos genéticos em busca de novos compostos bioquímicos, com a finalidade de que seus princípios ativos possam ser utilizados para a produção de novos produtos ${ }^{33}$.

O que tem acontecido em relação à biopirataria demonstra que não há interesse em atender preocupações humanitárias, mas, tão somente questões comerciais onde o conhecimento tradicional é expropriado, sem autorização dos seus detentores. Em prol de um benefício privado, os interesses são protegidos por meio de um sistema de propriedade intelectual internacionalmente estabelecido e que não assegura os direitos dos povos que secularmente desenvolveram técnicas e habilidades para extrair da natureza, de forma sustentável, sua subsistência física, espiritual e medicinal.

Com isso, em face da alienação da natureza e, no sentido, de se superar a hegemonia do aspecto mercantil patentário, é necessário reforçar e tutelar de forma efetiva os direitos dos povos, não admitindo-se a perpetuação de um contexto de conveniências econômicas, contexto esse em que os conhecimentos tradicionais somente possuem valor quando "mascarado" de cientificidade e potencial econômico. Portanto, pretende-se tecer no próximo momento do presente estudo as perspectivas para que se chegue à efetivação da proteção da sociobiodiversidade, até então reduzida, axiologicamente, ao interesse econômico.

\section{PERSPECTIVAS RUMO À PROTEÇÃO DA SOCIOBIODIVERSIDADE}

O meio ambiente natural, ao qual o ser humano se integra caracteriza-se como um conjunto complexo, na união entre diferentes fios transformados em uma só coisa, o que não significa homogeneidade. Dessa forma, tem-se o meio ambiente como as diversidades das complexidades que se uniram ${ }^{34}$ e influenciadas por

32 PORTO-GONÇALVES, Carlos Walter. A globalização da natureza e a natureza da globalização. 3.ed. Rio de Janeiro: Civilização Brasileira, 2012. p.317.

33 SANTILLI, Juliana. Socioambientalismo e novos direitos: proteção jurídica à diversidade biológica e cultural.

${ }^{34}$ MORIN, Edgar. Ciência com consciência. Rio de Janeiro: Bertrand Brasil, 2005. p.188. 
DAVIES, Lorenice Freire; KASSLER, Márcia Samuel. A apropriação ambiental no sistema de patentes biotecnológicas e a perspectiva de inclusão dos conhecimentos tradicionais como direito. Revista Eletrônica Direito e Política, Programa de Pós-Graduação Stricto Sensu em Ciência Jurídica da UNIVALI, Itajaí, v.10, n.1, edição especial de 2015. Disponível em: www.univali.br/direitoepolitica - ISSN 1980-7791.

esses paradigmas complexos, as sociedades são percebidas, para além de uma fonte de cultura-identidade comum a indivíduos diversos, uma vez que esses reconhecem as culturas e suas especificidades. Estas diferenças influenciadas pelo citado paradigma são mediadas por interações, que constituem ações também entre unidades complexas, estabelecendo desta forma uma auto-ecoreorganização ${ }^{35}$.

A sociodiversidade é formada pela imensa diversidade humana de culturas e costumes distintos, com destaque às etnias indígenas diferentes, populações quilombolas e comunidades tradicionais das mais diversas regiões do país ${ }^{36}$. São esses povos que convivem e conhecem a biodiversidade, interagindo com ela de forma harmônica, contribuindo para sua evolução genética, bem como na conservação e ampliação de espécies e de ecossistemas ${ }^{37}$.

Explica Alaim Giovani Fortes Stefanello que da reunião entre sociodiversidade e biodiversidade forma-se, então, a palavra "sociobiodiversidade". O termo foi conceituado por meio da Portaria Interministerial no 239, de 21 de junho de 2009, como a "inter-relação entre a diversidade biológica e a diversidade de sistemas socioculturais" ${ }^{\prime 38}$.

Assim, na atualidade, a expressão sociobiodiversidade denota uma proposta de unir a luta dos povos tradicionais com a luta ambiental, ampliando-a, contudo, para uma perspectiva maior no rumo da proteção dos diretos dos povos tradicionais e na manutenção do meio ambiente como valores pertencentes não apenas a uma categoria dos povos, mas a toda a humanidade. Consoante essa premissa, a biodiversidade e os conhecimentos tradicionais de culturas diversas atrelados aos recursos naturais, tanto vegetais ou animais, delineia a compreensão da sociobiodiversidade, o que permite o enlace da complexidade do vínculo humano e ambiental.

\footnotetext{
35 MORIN, Edgar. Ciência com consciência. p. 260.

36 STEFANELLO, Alaim Giovani Fortes. Do Direito Ambiental aos Direitos da Sociobiodiversidade: fundamentos e perspectivas. In: SOUZA FILHO, Carlos Frederico Marés de; FERREIRA, Heline Sivini; NOGUEIRA, Caroline Barbosa Contente. Direito socioambiental: uma questão para a América Latina. Curitiba: Letra da Lei, 2014. p.89.

37 DUTFIELD, Graham. Repartindo benefícios da biodiversidade: Qual o papel do sistema de patentes? In: PLATIAU, Ana Flávia Barros; VARELLA, Marcelo Dias (org.). Diversidade biológica e conhecimentos tradicionais. Belo Horizonte: Del Rey, 2004. p.202.
}

38 STEFANELLO, Alaim Giovani Fortes. Do Direito Ambiental aos Direitos da Sociobiodiversidade: fundamentos e perspectivas. p.89. 
DAVIES, Lorenice Freire; KASSLER, Márcia Samuel. A apropriação ambiental no sistema de patentes biotecnológicas e a perspectiva de inclusão dos conhecimentos tradicionais como direito. Revista Eletrônica Direito e Política, Programa de Pós-Graduação Stricto Sensu em Ciência Jurídica da UNIVALI, Itajaí, v.10, n.1, edição especial de 2015. Disponível em: www.univali.br/direitoepolitica - ISSN 1980-7791.

Contrapondo-se a essa lógica, de outra forma, percebe-se que em privilégio dos interesses econômicos, do lucro desmedido em detrimento do meio ambiente natural, impera a lógica desumana do mercado em desconsideração aos conhecimentos tradicionais e ao equilíbrio ambiental assegurado pela biodiversidade. Nesse sentido, observa-se a partir do sistema de patentes, a concepção mercantil, onde somente evidencia-se a sociobiodiversidade recursos naturais e conhecimentos tradicionais - quando atestada cientificamente a sua potencialidade econômica e viabilidade de produção capitalista, o que de outra forma, traduz-se na capitalização da natureza. São essas características de viés mercantil, que justificam a razão da existência de um sistema de patentes, pois utilizado como instrumento de retorno do investimento financeiro.

A partir da premissa da mercantilização da natureza, é importante pensar na perspectiva da sustentabilidade, visto que ela norteia, condiciona e modela o desenvolvimento. Trata-se de um paradigma de renovação indispensável de costumes, a opção maior pela dignidade da vida ${ }^{39}$.

A sustentabilidade é multidimensional, e as suas dimensões (social, econômica, ambiental, político-jurídica, ética) se entrelaçam, conforme explica o doutrinador Juarez Freitas:

Tais dimensões (ética, jurídico-política, ambiental, social e econômica) se entrelaçam e se constituem mutuamente, numa dialética da sustentabilidade, que não pode, sob pena de irremediável prejuízo, ser rompida. Não se trata, como visto, da singela reunião de características esparsas, mas de dimensões intimamente vinculadas, componentes essenciais à modelagem do desenvolvimento. De fato. Condicionamno ${ }^{40}$.

No enfoque da dimensão social da sustentabilidade, destaca-se como perspectiva de paradigma sustentável, o engajamento na causa do desenvolvimento que faça a sociedade sobreviver, a longo prazo, com dignidade e respeito ao valor intrínseco dos demais seres vivos. Ainda, o incremento intra e intergeracional,

\footnotetext{
${ }^{39}$ FREITAS, Juarez. Sustentabilidade: Direito ao futuro. 2.ed. Belo Horizonte: Fórum, 2012. p.83.

${ }^{40}$ FREITAS, Juarez. Sustentabilidade: Direito ao futuro.p.71.
} 
DAVIES, Lorenice Freire; KASSLER, Márcia Samuel. A apropriação ambiental no sistema de patentes biotecnológicas e a perspectiva de inclusão dos conhecimentos tradicionais como direito. Revista Eletrônica Direito e Política, Programa de Pós-Graduação Stricto Sensu em Ciência Jurídica da UNIVALI, Itajaí, v.10, n.1, edição especial de 2015. Disponível em: www.univali.br/direitoepolitica - ISSN 1980-7791.

bem como uma gestão aperfeiçoada de processos que garantam condições propícias ao florescimento virtuoso das potencialidades humanas ${ }^{41}$.

A diversidade de culturas representa uma alternativa à monocultura, à homogeneidade e à uniformidade. Conforme explica Vandana Shiva, "a semente viva torna-se um sistema de resistência contra as monoculturas e os direitos de monopólio" ${ }^{42}$.

Assim, passar da uniformidade para a diversidade é essencial tanto ecológica quanto politicamente. É um imperativo ecológico porque apenas um sistema baseado na diversidade respeita os direitos de todas as espécies e é sustentável. Também é um imperativo político porque a uniformidade anda de mãos dadas com a centralização, enquanto a diversidade requer um controle descentralizado ${ }^{43}$.

A diversidade, enquanto maneira de pensar e enquanto maneira de viver é necessária para superar o empobrecimento gerado pelas monoculturas mentais ${ }^{44}$. No tocante às comunidades locais, os seus direitos "é o seu controle, o seu saber e os seus direitos que (...) precisam ser fortalecidos se quisermos que a preservação da biodiversidade seja real e profunda. Esse fortalecimento tem de ser feito por meio da ação local, da ação nacional e da ação global"45.

A autora Vandana Shiva apresenta um caminho para remediar o sistema estruturado pode ser encontrado por meio do bioimperialismo, que se traduz no desequilíbrio Norte-Sul, a fim de também reconhecer as contribuições das comunidades locais para o desenvolvimento da biodiversidade ${ }^{46}$. Isto é, Vandana Shiva propõe que o atual regime pode ser regime seja substituído por outro, através das estruturas da biodemocracia.

\footnotetext{
${ }^{41}$ FREITAS, Juarez. Sustentabilidade: Direito ao futuro. p.306.

42 SHIVA, Vandana. Monoculturas da mente: perspectivas da biodiversidade e da biotecnologia. Tradução de Dinah de Abreu Azevedo. São Paulo: Gaia, 2003. p.17.

43 SHIVA, Vandana. Monoculturas da mente: (...) p.19.

44 SHIVA, Vandana. Monoculturas da mente: (...) p.19.

45 SHIVA, Vandana. Monoculturas da mente: (...) p.113.

${ }^{46}$ SHIVA, Vandana. Monoculturas da mente: (...).
} 
DAVIES, Lorenice Freire; KASSLER, Márcia Samuel. A apropriação ambiental no sistema de patentes biotecnológicas e a perspectiva de inclusão dos conhecimentos tradicionais como direito. Revista Eletrônica Direito e Política, Programa de Pós-Graduação Stricto Sensu em Ciência Jurídica da UNIVALI, Itajaí, v.10, n.1, edição especial de 2015. Disponível em: www.univali.br/direitoepolitica - ISSN 1980-7791.

A biodemocracia baseia-se no reconhecimento e respeito do valor intrínseco dos seres vivos e seu próprio direito ao êxito, bem como ao reconhecimento dos direitos originais dos povos que evoluíram conjuntamente com a biodiversidade de determinado local ${ }^{47}$. Para isso, entende-se que os Estados devem proteger esses direitos dos interesses monopolistas de apropriação privada dos seres vivos por meio de patenteamento, o que poderá ocorre por meio da descentralização dos direitos à biodiversidade.

Nesse sentido, destaca-se a importância de que os chamados "governos do Sul"48 se fortaleçam por meio do fortalecimento de seu povo e sua biodiversidade, protegendo os direitos democráticos à vida (nisso inclusos os indivíduos, a fauna e a flora). Dessa forma se poderá fortalecer os direitos soberanos à biodiversidade e a proteção contra impérios globais da era biotecnológica que se constroem com base na "(...) destruição e colonização da biodiversidade do Sul" ${ }^{49}$.

Também como perspectiva de proteção dos direitos intelectuais coletivos, verifica-se que a autora Juliana Santilli reporta a um regime jurídico sui generis, com o reconhecimento de sujeitos com a titularidade coletiva dos povos indígenas, quilombolas e populações tradicionais. Com pressupostos na identidade cultural coletiva e a usos, costumes e tradições coletivamente desenvolvidos, reproduzidos e compartilhados ${ }^{50}$. Representa, assim, uma alternativa devido à falta de consenso da temática, contudo, esta perspectiva também se enquadra (e representa) na forma de mercantilização da natureza.

De outro modo, a biodiversidade e o conhecimento das comunidades tradicionais não devem ser tratados como simples mercadoria, conforme entendimento de Karl Marx, passível de troca e com valor de uso ${ }^{51}$. A natureza não pode ser vista

\footnotetext{
${ }^{47}$ SHIVA, Vandana. Monoculturas da mente: (...). p.115.

${ }^{48}$ SHIVA, Vandana. Monoculturas da mente: (...) p.115.

${ }^{49}$ SHIVA, Vandana. Monoculturas da mente: (...). p.115.

${ }^{50}$ SANTILLI, Juliana. A biodiversidade e os povos tradicionais.p.175.

${ }^{51}$ MARX, Karl. O Capital: crítica da economia política. Livro Primeiro - o processo de produção de capital. Vol.1. 28.ed. Tradução de Reginaldo Sant'Anna. Rio de Janeiro: Civilização Brasileira, 2011. p.112.
} 
DAVIES, Lorenice Freire; KASSLER, Márcia Samuel. A apropriação ambiental no sistema de patentes biotecnológicas e a perspectiva de inclusão dos conhecimentos tradicionais como direito. Revista Eletrônica Direito e Política, Programa de Pós-Graduação Stricto Sensu em Ciência Jurídica da UNIVALI, Itajaí, v.10, n.1, edição especial de 2015. Disponível em: www.univali.br/direitoepolitica - ISSN 1980-7791.

como simples capital e a regulação estatal se faz impositiva para coibir o desvio comum dos adeptos do fundamentalismo voraz de mercado, que ignoram a complexidade do mundo natural ${ }^{52}$.

Outra perspectiva remete à importância de se utilizar, nas discussões sobre propriedade intelectual, a análise (ou estudo) cultural. Esta análise possibilita uma melhor compreensão e reflexão sobre as articulações dos modelos (eurocêntricos) que são impostos, os quais são aceitos com naturalidade pela sociedade, com pouca (ou sem) expectativa de transformação, como, por exemplo, o (atual) modelo do desenvolvimento econômico, o qual está engendrado na cultura da racionalidade do lucro, dentre outros.

A cultura condiciona a visão de mundo do homem. Conforme o autor Roque de Barros Laraia, os indivíduos discriminam comportamentos desviantes porque a sua herança cultural, desenvolvida através de inúmeras gerações, sempre os condicionou a reagir depreciativamente em relação ao comportamento daqueles que agem fora dos padrões aceitos pela maioria da comunidade ${ }^{53}$.

Cada sistema cultural está sempre em mudança e é importante compreender esta dinâmica para atenuar o choque entre as gerações e evitar comportamentos de preconceitos, bem como entender as diferenças existentes dentro de um mesmo sistema, etc. "Este é o único procedimento que prepara o homem para enfrentar serenamente este constante e admirável mundo novo do porvir" ${ }^{\prime 54}$. Esta é a importância da análise cultural.

Diante destas observações acerca da necessária consideração e perspectivas da inclusão dos conhecimentos tradicionais como direito, bem como para a efetiva proteção da sociobiodiversidade, é que o sistema de patentes deveria ser (re)pensado. Pois, reconhecer as diferentes culturas e seus conhecimentos tradicionais vinculados aos seus modos de vida, brinda a humanidade com importantes noções de solidariedade, cooperação e proteção ambiental.

\footnotetext{
52 FREITAS, Juarez. Sustentabilidade: Direito ao futuro. p.66.

53 LARAIA, Roque de Barros. Cultura: um conceito antropológico. 24 ed. Rio de Janeiro: Zahar, 2009. p.67.

54 LARAIA, Roque de Barros. Cultura: um conceito antropológico. p.101.
} 
DAVIES, Lorenice Freire; KASSLER, Márcia Samuel. A apropriação ambiental no sistema de patentes biotecnológicas e a perspectiva de inclusão dos conhecimentos tradicionais como direito. Revista Eletrônica Direito e Política, Programa de Pós-Graduação Stricto Sensu em Ciência Jurídica da UNIVALI, Itajaí, v.10, n.1, edição especial de 2015. Disponível em: www.univali.br/direitoepolitica - ISSN 1980-7791.

Nesse patamar de proteção e concepção integral do direito, poderíamos elencar um dos principais fundamentos dos direitos da sociobiodiversidade, o direito à vida em todas as suas perspectivas, onde os humanos e a natureza, em conjunto, seriam titulares de direitos dentro de uma visão integral e simbiótica, de cooperação. Vislumbra-se, então, a perspectiva que supera a visão tradicional de assegurar aos seres vivos não humanos uma proteção apenas em razão do benefício econômico do ser humano, para chegar a uma nova concepção de direitos, numa perspectiva de simbiose entre todos os seres vivos e demais elementos que compõem a natureza, admitindo-se uma ética de respeito e de satisfação mútua das necessidades da natureza e dos humanos dentro dos critérios de harmonia e , notoriamente, em específico ao objetivo desse estudo, a observância a dignidade, aos direitos fundamentais e humanos dos povos tradicionais.

\section{CONSIDERAÇÕES FINAIS}

A apropriação voraz dos recursos naturais e dos conhecimentos tradicionais associados promove uma aceleração da insustentabilidade ambiental. Apoiada por um sistema de propriedade intelectual que legitima essa forma de mercantilização dos saberes locais, a biotecnologia expande seus lucros e sua influência nas negociações que envolvem a proteção do meio ambiente.

O contexto acima mencionado deve ser superado, pois em se tratando da consideração apenas dos interesses econômicos e sua lógica patrimonialista e excludente, desconsidera-se os valores humanos e naturais para a existência do complexo contexto dinâmico entre o humano e o meio natural. Eis o desafio a ser aceito pelo sistema de patentes, pois do contrário estará perpetuando um cenário de trocas desiguais, onde os benefícios, para além dos econômicos concentram-se nas mãos de poucos, comprometendo a qualidade de vida e o futuro de muitos, sejam humanos ou não-humanos.

Portanto, a inclusão dos conhecimentos tradicionais como direito é ressaltada para a construção de uma efetiva proteção da sociobiodiversidade, ou seja, devese apreciar aquele enquanto elementar a ser considerado pelo sistema de patentes. Dessa forma, as diferentes culturas e os seus conhecimentos são realmente valorizados, pois para além da justa e equitativa repartição dos 
DAVIES, Lorenice Freire; KASSLER, Márcia Samuel. A apropriação ambiental no sistema de patentes biotecnológicas e a perspectiva de inclusão dos conhecimentos tradicionais como direito. Revista Eletrônica Direito e Política, Programa de Pós-Graduação Stricto Sensu em Ciência Jurídica da UNIVALI, Itajaí, v.10, n.1, edição especial de 2015. Disponível em: www.univali.br/direitoepolitica - ISSN 1980-7791.

benefícios econômicos, oriundos da exploração dos seus saberes e recursos naturais encontrados consigo, se reconhecem a condição de sujeitos de direitos e importantes atores na preservação do meio ambiente natural.

\section{REFERÊNCIAS DAS FONTES CITADAS}

ACSELRAD, Henri; MELLO, Cecília Campello. O que é justiça ambiental. Rio de Janeiro: Garamond, 2009.

BRASIL. Constituição da República Federativa do Brasil [1988]. Disponível em: <http://www.planalto.gov.br/ccivil_03/constituicao/constituicao.htm>. Acesso: 20.dez.2013.

BRASIL. Convenção sobre Diversidade Biológica [2000]. Disponível em < http://www.mma.gov.br/biodiversidade/convencao-da-diversidade-biologica $>$.

Acesso: 20. dez.2013.

DANTAS, Fernando Antonio de Carvalho. Los pueblos indígenas brasileños y los derechos de propriedad intelectual. In: Nuevos colonialismos del capital. Propriedad intelectual, biodiversidad y derechos de los pueblos. In: RUBIO, David Sánches; ALFARO, Norman J. Solórzano; CID, Isabel V.Lucena (orgs). Barcelona: Icaria Editoria, 2004.

DEERE, Carolyn. The implementation game: the TRIPS Agreement and the Global Politics of intellectual property reform in developing countries. New York (EUA): Oxford University Press, 2011.

DIEGUES, Antonio Carlos. A educação ambiental e a questão das áreas naturais protegidas. Disponível em: <http://nupaub.fflch.usp.br/sites/nupaub.fflch.usp.br/files/color/educamb.pd f>. Acesso em: 20 dez. 2013. p.9.

DUTFIELD, Graham. Repartindo benefícios da biodiversidade: Qual o papel do sistema de patentes? In: PLATIAU, Ana Flávia Barros; VARELLA, Marcelo Dias (org.). Diversidade biológica e conhecimentos tradicionais. Belo Horizonte: Del Rey, 2004.

FREITAS, Juarez. Sustentabilidade: Direito ao futuro. 2.ed. Belo Horizonte: Fórum, 2012.

HANNIGAN, John. Sociologia ambiental. Petrópolis: Ed. Vozes, 2009.

INOUE, Cristina Yume Aoki. Regime global de biodiversidade: o caso Mamirauá. Brasília, Ed. Universidade de Brasília, 2007.

LARAIA, Roque de Barros. Cultura: um conceito antropológico. 24 ed. Rio de Janeiro: Zahar, 2009. 
DAVIES, Lorenice Freire; KASSLER, Márcia Samuel. A apropriação ambiental no sistema de patentes biotecnológicas e a perspectiva de inclusão dos conhecimentos tradicionais como direito. Revista Eletrônica Direito e Política, Programa de Pós-Graduação Stricto Sensu em Ciência Jurídica da UNIVALI, Itajaí, v.10, n.1, edição especial de 2015. Disponível em: www.univali.br/direitoepolitica - ISSN 1980-7791.

LEFF, Enrique. Saber Ambiental: sustentabilidade, racionalidade, complexidade. Trad. Lúcia Orth. Petrópolis, RJ: Vozes, 2011.

MARX, Karl. O Capital: crítica da economia política. Livro Primeiro - o processo de produção de capital. Vol.1. 28.ed. Tradução de Reginaldo Sant'Anna. Rio de Janeiro: Civilização Brasileira, 2011.

MORIN, Edgar. Ciência com consciência. Rio de Janeiro: Bertrand Brasil, 2005.

NERO, Patrícia Aurélia. Propriedade intelectual: A tutela jurídica da biotecnologia. São Paulo: RT, 2004.

OST, François. A natureza à margem da lei: a ecologia à prova do direito. Lisboa: Ed. Instituto Piaget, 1995.

PORTO-GONÇALVES, Carlos Walter. A globalização da natureza e a natureza da globalização. 3.ed. Rio de Janeiro: Civilização Brasileira, 2012.

O desafio ambiental. Rio de Janeiro: Record, 2004.

PRONER, Carol. Propriedade Intelectual: para uma outra ordem jurídica possível. Cortez Editora, São Paulo: Brasil. 2007. Disponível em <http://bibliotecavirtual.clacso.org.ar/ar/libros/varios/Proner_2007.pdf>.Acesso: 20.dez.2013.

RUBIO, David Sánchez; ALFARO, Norman J. Solórzano. Introdución. In: RUBIO, David Sánchez; ALFARO, Norman J. Solórzano; CID, Isabel V. Lucena (org.). Nuevos colonialismos del capital: propiedad intelectual, biodiversidad y derechos de los pueblos. Barcelona: Icaria, 2004.

SANTILLI, Juliana. A biodiversidade e os povos tradicionais. In.: BENSUSAN, Nurit (org.). Seria melhor mandar ladrilhar? Como, para que e por quê?. 2 ed. Brasília: Universidade de Brasília, 2008.

Socioambientalismo e novos direitos: proteção jurídica à diversidade biológica e cultural. São Paulo: Peirópolis, 2012.

SANTOS, Laymert Garcia dos. Quando o conhecimento tecnocientífico se torna predação hight-tech: recursos genéticos e conhecimento tradicional no Brasil. In: SANTOS, Boaventura de Sousa (org.). Semear outras soluções: os caminhos da biodiversidade e dos conhecimentos rivais. Rio de Janeiro: Civilização Brasileira, 2005.p.127-165.

SHIVA, Vandana. Monoculturas da mente: perspectivas da biodiversidade e da biotecnologia. Tradução de Dinah de Abreu Azevedo. São Paulo: Gaia, 2003.

STEFANELLO, Alaim Giovani Fortes. Do Direito Ambiental aos Direitos da Sociobiodiversidade: fundamentos e perspectivas. In: SOUZA FILHO, Carlos Frederico Marés de; FERREIRA, Heline Sivini; NOGUEIRA, Caroline Barbosa 
DAVIES, Lorenice Freire; KASSLER, Márcia Samuel. A apropriação ambiental no sistema de patentes biotecnológicas e a perspectiva de inclusão dos conhecimentos tradicionais como direito. Revista Eletrônica Direito e Política, Programa de Pós-Graduação Stricto Sensu em Ciência Jurídica da UNIVALI, Itajaí, v.10, n.1, edição especial de 2015. Disponível em: www.univali.br/direitoepolitica - ISSN 1980-7791.

Contente. Direito socioambiental: uma questão para a América Latina. Curitiba: Letra da Lei, 2014.

VIEIRA, Vinícius Garcia. Direito da Biodiversidade e América Latina: a questão da propriedade intelectual. Ijuí; Unijuí, 2012.

Submetido em: Setembro/2014

Aprovado em: Outubro/2014 